\title{
Marketing as Control of Human Interfaces and Its Political Exploitation
}

\section{Luciano Floridi $^{1,2}$}

Published online: 10 August 2019

(C) Springer Nature B.V. 2019

\section{Introduction: Understanding Ourselves}

There is an endless number of ways to describe anything, including ourselves. In a more formal context, this is made clear and precise by speaking of levels of abstraction (Floridi 2008). ${ }^{1}$ Social scientists prefer to speak of "lenses", but the idea is the same. The point is not whether a description is accurate in absolute terms (is John a featherless biped? Or the details on his passport? Or $60 \%$ water and $40 \%$ something else? Or...) but whether it fulfils its purpose, and how well it does so, when compared with other descriptions. When we think that a description is the only one available, this is usually because we take its purpose for granted. Thus, we may describe an artefact as a "vehicle" because we take for granted a specific function or purpose of that artefact, but that description could easily change, if, for example, it is the SS-100-X presidential limousine in which Kennedy was a passenger when he was assassinated. All of a sudden "vehicle" is not wrong, but no longer satisfactory. This is the linguistic function of "just": it is no longer "just" a vehicle. John is no longer "just" a featherless biped or the details on his passport, because he is John Fitzgerald Kennedy, the 35th president of the USA assassinated in 1963.

Back to us, today, it makes a lot of sense to describe ourselves as informational organisms, or inforgs for short (Floridi 2014), in order to understand why and how we interact, flourish, or suffer depending on the flows of information in which we partake. This is related to what has been interestingly argued by Vilem Flusser:

\footnotetext{
${ }^{1}$ A level of abstraction can be imagined as an interface that enables one to observe or describe some aspects of a system analysed, while making other aspects opaque or indeed invisible. For example, one may analyse a house at the LoA of a buyer, of an architect, of a city planner, of a plumber, and so on. LoAs are common in computer science, where systems are described at different LoAs (computational, hardware, user-centred, etc.). Note that LoAs can be combined in more complex sets and can be, but are not necessarily hierarchical, with higher or lower "resolution" or granularity of information.
}

Luciano Floridi

luciano.floridi@oii.ox.ac.uk

1 Oxford Internet Institute, University of Oxford, 1 St Giles, Oxford OX1 3JS, UK

2 The Alan Turing Institute, 96 Euston Road, London NW1 2DB, UK 
The human being can no longer be seen as an individual but rather as the opposite, as a dense scattering of parts; he is calculable. The notorious Self is seen as a knot in which different fields cross, as in the way the many physical fields cross with the ecological, psychic, and cultural. The notorious Self shows itself not as a kernel but as a shell. It holds the scattered parts together, contains them. It is a mask. (Flusser 2005, p. 324)

I agree (Floridi 2011), but contrary to Flusser, I am not making an ontological, absolute point. I am making an epistemological and relational one. It should now be clear that I am not arguing that we are "just" inforgs (the self is not just a mask). Rather, I am suggesting that an informational level of abstraction to understand our identities, roles, behaviours, and interactions, is helpful and possibly the most adequate approach to interpret our human predicament today.

Describing ourselves as (also) inforgs, who forage for, produce, cultivate, curate, process, and consume information, inhabiting an environment also made of data and computational processes, means adopting an ecological perspective (Floridi 2013). When this is interpreted in social, economic, and political terms, then I would argue that we can upgrade our level of abstraction and understand ourselves not only as inforgs but also, and preferably, as interfaces. It is still an informational level of abstraction, but now we are focusing on a crucial, functional aspect that otherwise remains hidden. By describing ourselves as interfaces, we can understand more insightfully several crucial phenomena that characterise our digital age, including marketing and the "marketisation" of political communication, and what we can do about them. The rest of the article offers a series of clarifications in support of this statement and looks at some of its implications in political theory.

\section{Humans as Interfaces}

The initial point is quite simple (see Fig. 1), but it soon gets complicated. We are all becoming, more and more, human interfaces, that is, spaces of interactions between, on one side (human, artificial, or hybrid) interfacing agents, who want something from us, and, on the other side, something that (at least in theory if not in practice) we have, and which they want, the interfaced resources. The goal of these interactions is to enable effective operation and control of the interfaced resources from the side of the interfacing agents, whilst the interfaced resources feedback information that helps the agents' (decision-making) processes.

The transformation of people into human interfaces happens in many contexts, but three are crucial. For the world of social media, we are interfaces (human interface (HI)) between them (interfacing agent (IA)) and our personal data (interfaced resource (IR)). For the world of commerce, we (HI) are interfaces between them (IA) and our money or credit (IR). And for the world of politics, we are interfaces (HI) between them (IA) and our attention, consent, and votes (IR). I could go on, but these are the most significant contexts. They are interlinked and represent the social places (the markets) where the users, the consumers, and the citizens deal, on the supply side, with the main "demands", by social media, commerce (which includes advertisement), and politics (I shall provide two more examples below: education and health care). 


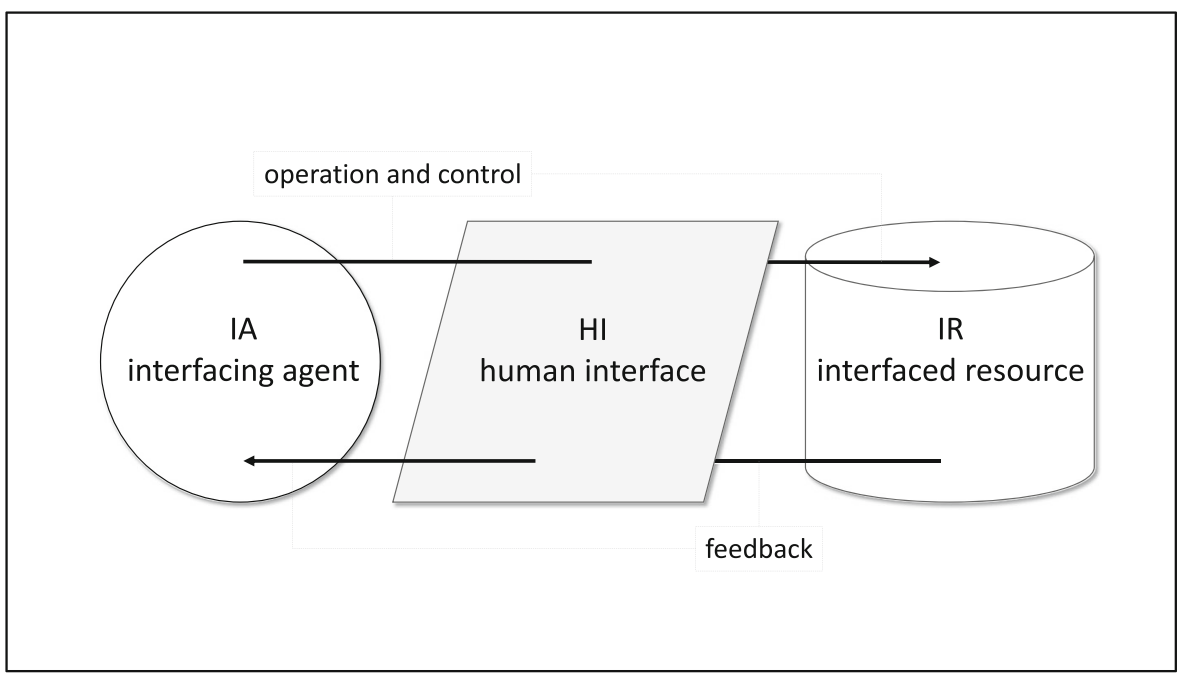

Fig. 1 The basic model of a human interface

As I mentioned earlier, it is helpful to describe ourselves as interfaces because it enables one to clarify some crucial processes and hence have a better grasp of what could be done in order to improve them, if one does not like them.

The first clarification concerns who the interfaces are exactly. It would be foolish to think that there is really a fixed and immutable role between the "interfacing them", as "they are always the agents who handle the interfaces", and ourselves, as "we are always the interfaces". In technical terms, "we" and "they" are indexical, which change reference depending on the context of use. In reality, "we" can also become "they", and vice versa, depending on the perspective. More specifically, as users, we are also the interfacing agents (IA) who use social media as interfaces (HI) between us and their services (IR); as consumers, we are the interfacing agents (IA) who use companies as interfaces (HI) between us and their products (IR); and as citizens, we are the interfacing agents (IA) who use politics (or the politicians or the parties, the exact ontology does not matter here) as an interface (HI) between us and the society in which we would like to live (IR). It is easy to become confused in this game of mirrors or, better, of interfaces, but the point is quite simple: the roles in Fig. 1 are fixed, but who plays which role, how far and how well (think of biases, for example), changes contextually. With a final proviso, because each of us tends to be naturally self-centred, it is easier to see oneself as an interfacing agent (IA) using bits of the world as interfaces (HI) to try to obtain what one wants (IR), rather than as an interface (HI) used by bits of the world (IA) to obtain something the world wants from us (IR). This natural tendency is fully exploited by marketing strategies (more on them below), whenever they seek to make each individual feel to be the centre of their attention. A fully egocentric individual can hardly imagine to be just an interface used by others, and so it can be more easily manipulated and exploited. The current rhetoric of "disintermediation" and "user/consumer-centred (anything)" is a way of obfuscating the fact that, in the new reintermediation, the actual interfaces are us.

The second clarification concerns the process of transformation (conceptually and factually) of people into interfaces. It is clear that, when one talks about the 
transformation of a context into a market (henceforth marketisation), for example, in terms of a certain type of privatisation of a sector in view of some macroeconomic strategy, one should actually understand that, more precisely, as an "interfacisation" (transformation into, and use as, interfaces) of the people involved in that context. For example, transforming education into a market, with relations of demands and supplies, means transforming learners into customers, with interfacing agents - society, families, administrative organisations, and the various suppliers or service providers of education (note that the interfacing agents can be hybrid systems) - interested in something to which the learners, now the new customers, give access as interfaces, namely (success, in terms of), school results, targets, standards, or training performance. Such a success becomes the newly interfaced resource that they want. This interfaced resource is "accessed" through the learners/interfaces. And it becomes more understandable and comparable the more it is quantifiable, in terms of data, funding obtained, value for money, grades, successful applications, job placements, and so forth.

Or consider the marketisation of well-being and health care. This means turning people into interfaces between the interfacing agents, who are now the providers of the goods or services, and the parameters that determine some pre-set level of "well-being" or "health", the new interfaced resource, for example, the notorious 10,000 steps to do every day (Morley and Floridi 2019). Note, in this case, that not only are the roles between "them" and "us" interchangeable (who is the interface for whom?) but also that the interfacing agents can be artificial. To put it dramatically, an app becomes the interfacing agent that uses Alice as an interface to get to some pre-established performance (as a target) by Alice, the interfaced resource. Note, also, that actual user interfaces in the ordinary sense of the word (e.g., some visual information on an app) can easily refer to other interfacing agents (in this case the user of the app). This too can cause some confusion. And finally, the "interfacing game" soon becomes complicated because an app may also be a commercial product that is trying to get, through Alicethe-human-interface, to her interfaced data, money, or approval, or high rating, and so forth.

In all the previous cases, two procedural steps are fundamental: from the marketisation of a context to the interfacisation of the people involved in that context and from the interfacisation to the quantification of the criteria of whatever counts as success in obtaining the interfaced resource in that context. Individuals become keypads: get the numeric sequence right and you can "open" them to access what you need or want on the other side of the interaction. If, in real life, Alice uses "open sesame" as her password for a service, the joke is on her, because fiction now increasingly meets reality: she becomes what she thinks she is describing, an interface, and to use her as such, all Bob needs to do is to treat her as an interface with a password.

The use of human beings as mere interfaces (Wiener 1989) may not be necessarily done for evil purposes. The interfacing first, and then the utilisation of the interfaces after, may be done for the sake of the human keypads, e.g., to make them better educated or healthier. Yet, it is still not morally right, as I shall argue presently. This is a third clarification, which is ethical. Transforming and using individuals (users, consumers, citizens, learners, patients, etc.) simply as interfaces means not to respect their dignity as persons and to disregard what is ethically good for them intrinsically and individually. It contradicts the ethical principle, famously synthesised by Kant in the categorical imperative, that you should always "act in such a way that you treat 
humanity, whether in your own person or in the person of another, always at the same time as an end and never simply as a means" (Kant 2014). The only difference is that today, "treating simply as a means" is equivalent to "treating simply as an interface". Manipulating someone, in the almost literal sense of keypadding someone as a means or an interface to obtain something else, is perhaps the most common way to dehumanise that someone, treating a person, for example, as a slave or a robot. This is why the vision of ourselves as mere interfaces is unfortunately realistic and makes us shudder a bit.

Thus, we come to the fourth and final explanation. If we are all becoming more and more like interfaces - regardless of the considerable confusion that all this may cause and the fact that it is ethically appalling - how does the control and management of these interfaces work exactly? This is a crucial question à la Machiavelli (the Machiavelli of the Discourses, (Machiavelli 2008)), because it is brutally realistic and factual, but it is not (at least not yet) Machiavellian (Machiavelli 2019), because it is not meant to be amorally astute in recommending some special relationship between means and ends. I just pointed out that it is not even a Kantian question, because it does not ask (or at least not yet) how one goes about changing or improving the situation. The question calls for an objective and not-yet ethical understanding of the situation itself. It invites us to investigate the mechanisms and logic that underlie the phenomenon, perhaps in view of a subsequent transformation for the better. In short, it is a question that privileges the epistemological moment to the ethical one.

\section{Marketing as Control and Management of Human Interfaces}

As hinted by the title of this article, the answer is that today the control and management of human interfaces is marketing, or more generally the public relations and communication strategies from which the techniques of marketing descend. Marketing sees and uses people as interfaces. Its goal is to identify the most efficient and effective ways to use the human interfaces so as to obtain what the interfaces give access to, which, in politics, is represented, in logical order, by attention, consent, and vote. This is the topic on which I wish to focus in the rest of this article, for it seems that it is especially in politics that understanding how humans are seen and used as interfaces is particularly helpful to make sense of some current, populist trends and hence have a better chance to redress them.

The fact that marketing strategies and techniques dominate politics today, and not just the purchase and use of goods or services, is unfortunate, can be misleading, but should not be surprising. In a world in which humans are both seen and treated as interfaces, we are not witnessing the downgrading of politics to marketing, but rather the upgrading of marketing to politics, in terms of strategies for the successful interaction (operation and control) of the human interfaces that we have all now become. As I shall argue in the next section, the outcome is the same, but the process through which it is reached is different. Here, I wish to stress that understanding it helps one to get rid of another potential confusion. The digital revolution has radically transformed the power of marketing and made possible its upgrading to political communication thanks to the fact that we have oceans of personal data, that billions of people are now connected and live "onlife" (both online and offline (Floridi 2015)) 
in the infosphere, that algorithms are increasingly sophisticated, that the cost of computing power is becoming negligible, that network effects are dominating competition, and that social interactions are increasingly mediated by digital technologies. However, focusing only on these technological and social factors is insufficient because it explains only some necessary conditions to understand the marketisation of politics and hence political communication as a marketing technique. An essential element is still missing, and it is represented by the deeper transformation in our philosophical anthropology (the answer we give today to the ontological question about our nature). The digital revolution has changed our self-conception, culturally and socially. It has transformed all of us into inforgs, ontologically, and hence into interfaces, functionally. This has happened both at a conceptual (how we see ourselves) and at a factual (how we treat and interact with each other) level. It is this philosophical transformation that is also necessary to explain the fundamental upgrading of marketing into political communication and the deep influence that marketing strategies have on politics these days. Thus, it is too simplistic to speak of post-truth communication. We should rather speak of successful/unsuccessful communication: the goal is to key in the answers on the human interfaces that succeed in making them behave as desired and obtain the interfaced resource. Marketing is a form of nudging, and "push someone's buttons" is increasingly less of a metaphor and more an actual technique to describe interfaced interactions. The marketisation of political communication means that messages are like keywords: short, simple, always the same, repeated, and above all neither true nor false, but successful or not. If one does not like them, the best thing to do is to change the interface and its patterns of acceptance. This is why all the truths in the world have made very little difference about Trump or Brexit. The frustration of those who expect to see truth prevail in the political discourse - think of "speaking truth to power" or unveiling a behaviour that in the past would have ruined the career of any bad politician - is understandable, even shareable, but it is also anachronistic. This is regrettable, but the true/false approach does not work - not because insufficient truths have been provided, or too many falsehoods or contradictions still remain hidden, but because the true/false dichotomy has no grip on the human interfaces, a bit like keying in letters when the password is numeric: there is no right sequence of letters to be found in the first place. Post-truth is really post truth-and-falsehood. And so it is also post coherence/incoherence, again, not because more needs to be done-if anything, this is the age of recording, and there is an overabundance of digital material that exposes the blatantly contradictory and opportunistic communications of bad politicians - but because the tailoring of the messages, made possible by digital technologies, means that, in theory, each human interface can receive the successful message that is supposed to work, independently of other interfaces and hence other kinds of possibly inconsistent messages. Thus, the political manifesto, broadcasted to a whole population of potential voters, is an outdated, one-size-fits-all approach about which very few voters-interfaces care today. The trend is rather towards increasing specialisation of messages and a "bubblification" of the audience, all the way to one human interface= one human bubble. Marketing is Platonist by necessity but nominalist by ambition. And in its attempt to reach a one-to-one unique relation with each human interface, there can be no incoherence: Alice can use Bob-as-an-interface and Carol-as-aninterface by keying in different and even opposite messages, exactly in the same sense 
in which there can be no contradiction between two different passwords for two different interfaces.

\section{Political Communication as Marketing}

When people remark that politics has become a matter of marketing, it is important to understand why this is true. It is not because the digital revolution has shifted the domain of politics within the domain of marketing, as if, in a Venn diagram, the political circle had progressively moved inside the marketing circle. Instead, it is because the digital revolution has extended the power of marketing to the control and management of the interfaces/citizens and therefore of politics. It is the marketing circle that has expanded so much as to include the political circle. In the Venn diagram, politics has not moved; it is marketing that has hugely expanded and now encircles it. As I mentioned in the previous section, the outcome is the same, the final Venn diagram looks the same, but the trajectory of how we have reached such outcome is crucial. Because any improvement of politics will not come from a re-location of politics, as if politics had been temporarily derailed and all it could take to rectify the situation would be to put it back on track. As marketing expands its scope and reach and now includes political communication, the only way to improve political communication is to improve marketing itself. From this, at least two conclusions follow.

First, Berlusconi, Bolsonaro, Cháves, Di Maio, Duterte, Farage, Grillo, Johnson, Le Pen, Maduro, Orban, Putin, Salvini, Trump, and many other populists capable of saying anything and respecting nothing are, initially, the effect and not the cause of the extension of marketing to politics. As in the simplest of Darwinian contexts, they are the organisms that have benefited most from the change in the ecosystem, the marketisation of politics. Their fitness can be understood in terms of optimal marketing. Still lacking the possibility of a total customisation of the political message to the single human interface, populists seek to maximise the individual tailoring of a universal communication by identifying points of shared interest (e.g., lower taxes) or by creating points of common fear (e.g., xenophobia) among the human interfaces. Their marketing seeks to be Pareto optimal ${ }^{2}$ : it allocates messages to interfaces in such a way that it is impossible to reallocate the messages so as to work better with any one interface without working worse with at least another interface. Or more simply: populists seek to give to the human interfaces what the latter want and make them want what they can give them.

Once populists are in powerful or influential positions, their actions have an endogenous ecological impact: they are like extremophiles, ${ }^{3}$ who not only flourish in circumstances that are poisonous to any other form of political life but also contribute to such poisoning (more selfish interests, more shared fears), thus reinforcing a vicious circle in which the worse the environment is, the more likely it is that such political

\footnotetext{
${ }^{2}$ I am adapting this from economics, where "Pareto efficiency or Pareto optimality is a state of allocation of resources from which it is impossible to reallocate so as to make any one individual or preference criterion better off without making at least one individual or preference criterion worse off" (Wikipedia).

3 "An extremophile (from Latin extremus meaning "extreme" and Greek philiā ( $\varphi$ i $\lambda \dot{i} \alpha)$ meaning "love") is an organism that thrives in physically or geochemically extreme conditions that are detrimental to most life on Earth" (Wikipedia).
} 
extremophiles are the strongest species and the only one able to survive, thus further poisoning it. As long as the ecosystem does not change, this kind of political organisms will thrive. And if they disappear, similar ones will replace them. If one does not like them, one needs to improve the ecosystem that generates and feeds them, and that in turn is fed by them.

Which means, and this is the second consequence that I would like to underline, that if one wants to improve the situation, then one will have to work on improving the marketisation of politics, by relying on the interfacing process itself. We need to begin by improving the infosphere in which we live and the marketing processes that take place in it, not by trying to relocate politics, as if it were a piece of furniture in the living room, to be placed a little more to the right or a little more to the left. It is the whole room that needs to be improved, so to speak. This is why politicians like Corbyn in the UK, or parties like the Partito Democratico in Italy, are not in touch with the new morphology of politics and do not seem to represent a new future but an old past that tries to come back.

In a healthier environment, better political forces can prosper which can then improve the environment even further, progressively crowding out bad politics. One needs to remember that the Matthew effect ${ }^{4}$ and the network effect are dynamic processes that also work in the opposite direction: the more one loses, the further one ends up losing, like in a bank run; likewise, the less useful a network is, the less people participate, and so forth. ${ }^{5}$ The only good thing about a vicious circle (or a bad network effect) is that it can be reversed into a virtuous one (or a good network effect) that can grow as quickly. Populists can fail as rapidly as they can succeed. This leads to a concluding consideration about how one may start this inversion.

\section{Conclusion: Stealthy Democracy}

There seem to be three main possibilities. A polluted environment - in which the wrong kind of marketisation of politics makes the wrong kind of politics the only organism that can flourish-may (a) collapse by itself; (b) be devastated by external forces; or (c) be reformed, to pre-empt such collapse or devastation.

In (a), bad politics collapses under its own weight, so to speak, when it becomes so polluted to lead to systemic failure. This is the case of Venezuela today, for example. Its current status of crisis as a failed state seems to be almost entirely self-generated.

In (b), bad politics and its polluted environment may be devastated by other forces, such as revolutions, (civil) wars, health, or environmental disasters. This is often the lesson taught by history. Bad politics and populism lead to playbook steps: simplistic solutions in terms of fictional enemies, intolerance, xenophobia, hate, and finally conflict. Unimaginable suffering follows, which causes a final reaction. The history

\footnotetext{
${ }^{4}$ The term indicates the reinforcement of polarisation and takes its name from the famous text in Matthew 25:29: "For to everyone who has more will be given, and he will have abundance; but from him who has not, even what he has will be taken away".

5 "A bank run (also known as a run on the bank) occurs when a large number of people withdraw their money from a bank, because they believe the bank may cease to function in the near future" (Wikipedia). The more people withdraw their money, the higher the risk that the bank may actually cease to function, and the more people will withdraw their money, giving rise to a "self-fulfilling prophecy".
} 
of the twentieth century is full of horrific examples, from the Fascist dictatorships to the Soviet Union. Even in recent times, when populists do not know how else to maintain power and mobilise the human interfaces, they declare war. In 1981, Argentina's Third Military Junta ordered the invasion of the Falkland (Malvinas) Islands and South Georgia, seeking to establish the sovereignty it had claimed over them. This led to a conflict that "remains the largest air-naval combat operation between modern forces since the end of the Second World War". It was described by Borges as "a fight between two bald men over a comb". 6 Putin has been using the same strategy to distract Russia's public opinion and fuel nationalist support for his rule.

In both cases, (a) collapse and (b) devastation, politics fails to be its own cure. The spiral of bad politics exploiting human interfaces to beget more bad politics through the wrong kinds of marketisation of political communication ends in disaster. There is, however, a third, healthy possibility, namely (c), the democratic replacement of bad politics. Unfortunately, this is more difficult than it may seem because we have seen that the poisonous agents in power further poison the environment in which they flourish and seek to eliminate any other healthier and cleaner forces that may contrast them and undermine their ecology. This is why, when bad politics prevails, civil society does not react by engaging more, but rather ends up distancing itself from politics, seen as a hopeless choice among bad options. If change is not brought about by (a) the internal consumption of the logic of pollution (at some point everything dies and only suffering is left as a force of renewal) or caused externally by (b) dramatic events, and if ordinary, good politics becomes ineffective, what remains is change by stealth, or what I would like to call "stealthy democracy". For example, in the UK, it may be the reform of the voting age or the reform of the voting system used to elect MPs to the UK Parliament, from a First Past the Post system to a Proportional system, or the request of a new referendum on Brexit. These are entirely conventional and contingent features of the current predicament of British politics. To use Machiavelli's terminology, we need to recognise their dependency on fortuna (accident) and then move to identify what needs to be done accordingly (necessità, necessity) by stealth. Likewise, stealthy democracy may be implemented by appealing to external pressure, as many politicians in Europe have done, by referring to "Brussels" whenever in need to justify some unpopular yet positive and necessary changes. Today, in a world in which citizens are seen and used as interfaces, change by stealth may be achieved by the use of political marketing itself to gain attention, approval, and votes, by using topics, policy suggestions, promises, and a rhetoric that mimic those of the polluting politicians, without any actual intention of giving real course to the corresponding actions once in power. Change by stealthy democracy is not Machiavellian in the "Prince" sense but in the "Discourses" sense, i.e., it may be an extreme yet necessary solution (necessità) at a time when populism, nationalism, and xenophobia (all aspects of fortuna) are rampant, and the social and environmental crises dramatic. What is needed is not a rejection but a much better use of marketing strategies themselves, as a means to serve much better ends. Because a good end may not justify bad means, but it certainly motivates their improvement to deliver an even better end.

\footnotetext{
${ }^{6}$ https://www.theguardian.com/commentisfree/2010/feb/19/falkland-islands-editorial
} 
Acknowledgements A first version of this article was published as the Preface of Ambroso and Beulcke (2019). I am very grateful to Odoardo Ambroso and Alessandro Beulcke for their kind invitation and opportunity to develop my ideas on the topic and to Corinne Cath - Speth, Josh Cowls, Kia Nobre, Jessica Morley, and Mariarosaria Taddeo for their extremely valuable suggestions and feedback on this much expanded and revised version. They are to be praised for any improvement on past versions, not blamed for any remaining shortcomings in the current one.

\section{References}

Ambroso, O., \& Beulcke, A. (2019). Click propaganda. Come sfruttare il potere dei dati nella comunicazione politica. Milan: LSWR.

Floridi, L. (2008). The method of levels of abstraction. Minds and Machines, 18(3), 303-329.

Floridi, L. (2011). The informational nature of personal identity. Minds and Machines, 21(4), 549-566.

Floridi, L. (2013). The ethics of information. Oxford: Oxford University Press.

Floridi, L. (2014). The 4th revolution: How the infosphere is reshaping human reality. Oxford: Oxford University Press.

Floridi, L. (2015). The onlife manifesto: Being human in a hyperconnected era. Cham, Switzerland: Springer. Flusser, V. (2005). The city as wave-trough in the image-flood. Critical Inquiry, 31(2), 320-328.

Kant, I. (2014). Groundwork of the metaphysics of morals: A German-English edition. Cambridge: Cambridge University Press.

Machiavelli, N. (2008). Discourses on Livy. Oxford: Oxford University Press.

Machiavelli, N. (2019). The Prince (Second ed.). Cambridge: Cambridge University Press.

Morley, J., \& Floridi, L. (2019). Enabling digital health companionship is better than empowerment. The Lancet Digital Health.

Wiener, Norbert. 1989. The human use of human beings: Cybernetics and society. Revised edition. London: Free Association.

Publisher's Note Springer Nature remains neutral with regard to jurisdictional claims in published maps and institutional affiliations. 